\title{
Pressure overload-induced mild cardiac hypertrophy reduces left ventricular transmural differences in mitochondrial respiratory chain activity and increases oxidative stress
}

\author{
Michel Kindo 1,2, Sébastien Gerelli, ${ }^{1,2}$, Jamal Bouitbir ${ }^{2,3}$, Anne-Laure Charles ${ }^{2,3}$, Joffrey Zoll2,3, \\ Tam Hoang Minh ${ }^{1,2}$, Laurent Monassier ${ }^{4}$, Fabrice Favret ${ }^{2,5}$, François Piquard ${ }^{2,3}$ and Bernard Geny ${ }^{2,3 *}$ \\ 1 Service de Chirurgie Cardiovasculaire, Pôle d'activité médico-chirurgicale Cardiovasculaire, Hôpitaux Universitaires, CHRU Strasbourg, Strasbourg, France \\ 2 Equipe d'Accueil 3072, Faculté de Médecine, Institut de Physiologie, Université de Strasbourg, Strasbourg, France \\ ${ }^{3}$ Service de Physiologie et d'Explorations Fonctionnelles, Pôle de Pathologie Thoracique, Hôpitaux Universitaires, CHRU Strasbourg, Strasbourg, France \\ ${ }^{4}$ Laboratoire de Neurobiologie et de Pharmacologie, Université de Strasbourg, Strasbourg, France \\ ${ }^{5}$ Faculté des Sciences du Sport, Université de Strasbourg, Strasbourg, France
}

Edited by:

Kenneth S. Campbell, University of Kentucky, USA

Reviewed by:

Ravi C. Balijepalli, University of

Wisconsin, USA

Leonardo F. Ferreira, University of

Florida, USA

*Correspondence:

Bernard Geny, Service de

Physiologie et d'Explorations,

Fonctionnelles et Equipe d'Accueil

3072, Université et Hôpitaux

Universitaires de Strasbourg,

67091 Strasbourg, France.

e-mail: bernard.geny@

chru-strasbourg.fr

\begin{abstract}
Objective: Increased mechanical stress and contractility characterizes normal left ventricular (LV) subendocardium (Endo) but whether Endo mitochondrial respiratory chain complex activities is reduced as compared to subepicardium (Epi) and whether pressure overload-induced LV hypertrophy (LVH) might modulate transmural gradients through increased reactive oxygen species (ROS) production is unknown. Methods: LVH was induced by 6 weeks abdominal aortic banding and cardiac structure and function were determined with echocardiography and catheterization in sham-operated and LVH rats ( $n=10$ for each group). Mitochondrial respiration rates, coupling, content and ROS production were measured in LV Endo and Epi, using saponin-permeabilized fibers, Amplex Red fluorescence and citrate synthase activity. Results: In sham, a transmural respiratory gradient was observed with decreases in endo maximal oxidative capacity $(-36.7 \%, P<0.01)$ and complex IV activity $(-57.4 \%, P<0.05)$. Mitochondrial hydrogen peroxide $\left(\mathrm{H}_{2} \mathrm{O}_{2}\right)$ production was similar in both LV layers. Aortic banding induced mild LVH (+31.7\% LV mass), associated with normal LV fractional shortening and end diastolic pressure. LVH reduced maximal oxidative capacity $(-23.6$ and $-33.3 \%)$, increased mitochondrial $\mathrm{H}_{2} \mathrm{O}_{2}$ production $(+86.9$ and $+73.1 \%)$, free radical leak $(+27.2 \%$ and $+36.3 \%)$ and citrate synthase activity $(+27.2 \%$ and $+36.3 \%)$ in Endo and Epi, respectively. Transmural mitochondrial respiratory chain complex IV activity was reduced in LVH (-57.4 vs. $-12.2 \% ; P=0.02)$. Conclusions: Endo mitochondrial respiratory chain complexes activities are reduced compared to LV Epi. Mild LVH impairs mitochondrial oxidative capacity, increases oxidative stress and reduces transmural complex IV activity. Further studies will be helpful to determine whether reduced LV transmural gradient in mitochondrial respiration might be a new marker of a transition from uncomplicated toward complicated LVH.
\end{abstract}

Keywords: aortic banding, pressure overload, heart, hypertrophy, mitochondria, oxydative stress, transmural

\section{INTRODUCTION}

Chronic pressure overload (PO) is a frequent clinical occurrence that leads to left ventricular hypertrophy (LVH). Initially, LVH was considered to be a compensatory mechanism that allows the normalization of wall mechanical stress and generation of the required cardiac output (Opie et al., 2006). However, LVH is also a risk factor for the development of heart failure and sudden death from arrhythmias. Thus, systemic hypertension and aortic

Abbreviations: Endo, subendocardium; Epi, subepicardium; LV, left ventricular; $\mathrm{LVH}$, left ventricular hypertrophy; $\mathrm{PO}$, pressure overload; ROS, reactive oxygen species; $\mathrm{H}_{2} \mathrm{O}_{2}$, hydrogen peroxide. stenosis-induced LVH can become maladaptive and precede the onset of heart failure (Drazner, 2011). Accordingly, recent data support that enhanced post-operative LV mass regression after aortic valve replacement for aortic stenosis is associated with improved long-term survival (Ali et al., 2011).

LVH results from increased cardiomyocyte size induced by an increase in the number of intracellular organelles, including mitochondria. Mitochondria are the main energy powerhouses of cells, and they convert nutrients into energy through cellular respiration. Although no unique pattern of cardiac adaptation occurs in response to physiological or pathological hypertrophic stimuli, mitochondrial dysfunction and increased oxidative stress 
are the primary factors in LVH pathogenesis (Ventura-Clapier et al., 2001; Seddon et al., 2007; Takimoto and Kass, 2007; Rimbaud et al., 2009). Cardiac metabolic flexibility is crucial and during PO-induced cardiac hypertrophy, the heart shifts from fatty acids to glucose as the primary substrate for energy production. Later, in end-stage heart failure, mitochondrial dysfunction may reduce the rate of substrate oxidation, decreasing energy production and increasing the formation of reactive oxygen species (ROS) (Ventura-Clapier et al., 2001; Zoll et al., 2005; Seddon et al., 2007; Takimoto and Kass, 2007; Ingwall, 2009). Under conditions of high oxidative stress, cell dysfunction, necrosis and/or apoptosis are induced (Seddon et al., 2007; Takimoto and Kass, 2007).

Oxidative stress is related to an excess production of ROS originating from several sources in the heart. Besides mitochondria, xanthine oxidase, uncoupled nitric oxide synthases, inflammatory cells, and NADPH oxidases are largely involved in cardiac remodeling, including during cardiac PO (Murdoch et al., 2006; Nabeebaccus et al., 2011). ROS include several free radicals like superoxide anion, hydroxyl and the highly reactive compound hydrogen peroxide $\left(\mathrm{H}_{2} \mathrm{O}_{2}\right) . \mathrm{H}_{2} \mathrm{O}_{2}$, resulting from superoxide dismutase action on superoxide anion, is considered as the most relevant ROS signaling molecule in cells which can give rise to hydroxyls radicals and may impair mitochondrial respiration rates (Veal et al., 2007). We therefore investigated an eventual relationship between increased $\mathrm{H}_{2} \mathrm{O}_{2}$ production and $\mathrm{LV}$ subendocardium (Endo) and subepicardium (Epi) mitochondrial function.

Indeed, despite its frequency, relatively few data are available and whether impaired mitochondrial oxidative capacity occurs in mild cardiac hypertrophy is still discussed (Jameel and Zhang, 2009; Rimbaud et al., 2009; Van Bilsen et al., 2009; Griffiths et al., 2010).

Interestingly, in line with their different origins during embryologic development, the LV Endo and Epi present distinct characteristics in terms of blood flow, structure, metabolism, electrophysiological, and contractile properties (Whitty et al., 1976; Cazorla et al., 2005; Sengupta et al., 2006; Duncker and Bache, 2008; Van der Velden et al., 2011). Such transmural differences are well known but, whether they are associated with transmural differences in mitochondrial complex activities deserves further analysis. Indeed, differences in subendo- and Epi mitochondria or their regulation were expected but, previous reports showed no or minor differences when considering metabolic enzymes or electron transport system (Geshi et al., 1988; Gallego-Delgado et al., 2006). However, there are few data comparing endo- and epicardium layers mitochondrial function in the normal LV, especially using saponin-skinned fibers that ensure global mitochondrial function assessment in intact mitochondria (MacDonald et al., 2011).

The aim of this study was to challenge the hypothesis that, accordingly to the non-uniform properties of the LV wall, (1) mitochondrial respiratory chain complex activities of LV Endo are reduced as compared to Epi and (2) that increased mechanical wall stress that occurs in LVH might impair such a transmural respiratory gradient. To get insight in the mechanisms involved, we also investigated ROS production in the Endo and Epi layers through mitochondrial hydrogen peroxide measurements both in normal heart and after PO-induced LVH.

\section{METHODS}

Adult male Wistar rats (weight range 250-300 g) were used in the experiments. Animals were kept in a temperature- and humiditycontrolled room with a 12:12 h photoperiod and were provided with food and water ad libitum. The study conformed to the Guide for the Care and Use of Laboratory Animals published by the US National Institutes of Health and was approved by the institutional animal care committee.

\section{ANAESTHESIA AND EXPERIMENTAL DESIGN}

Twenty animals were randomly assigned to two groups of ten each. Sham-operated rats underwent a procedure similar to that applied to the LVH group except that the aorta was not banded in sham-operated animals. In the LVH group, the abdominal aorta was banded above the renal arteries. During the procedure, anaesthesia was induced with $3 \%$ isoflurane and oxygen ( $1 \mathrm{l} / \mathrm{min})$ in an induction chamber (Minerve, Esternay, France). After the peritoneum was opened, $5 \mathrm{mg} / \mathrm{kg}$ of intraperitoneal tramadol was administered. Anaesthesia was maintained with $1.5 \%$ isoflurane and $1 \mathrm{l} / \mathrm{min}$ oxygen at under spontaneous ventilation. The animal's core body temperature was maintained at $37^{\circ} \mathrm{C}$ using a controlled heating pad (Homeothermic blanket control unit, Harvard Apparatus $\left.{ }^{\circledR}\right)$. The suprarenal abdominal aorta was exposed after a laparotomy was performed. A 4-0 silk suture was used to tie off the suprarenal abdominal aorta using a blunted 22 gauge needle, which was then pulled out. Following the surgery, the animals' housing conditions were kept constant during a 6-week period.

In animal models of PO secondary to aortic banding, ventricular remodeling and function depend upon several factors including localization of the aortic banding, degree of aortic coarctation and age of the animal at the time of the surgery. Our experimental design was expected to induce a progressive LVH with no alteration of the systolic ventricular function. These parameters were chosen in order to mimic common clinical settings such as systemic hypertension or aortic stenosis.

\section{ECHOCARDIOGRAPHY AND CARDIAC REMODELLING}

Two days before the animals sacrifice, echocardiography was performed. The following parameters were measured in isofluraneanaesthetized rats by two-dimensional and Doppler echocardiography (Sonos 5500, Philips Ultrasound) with a $12-\mathrm{MHz}$ phasedarray transducer (S12): percentage of LV fractional shortening, LV ejection fraction, LV mass, heart rate, LV end-diastolic, and endsystolic diameter, septum wall thickness in diastole, posterior wall thickness in diastole and isovolumic relaxation time. The LV mass was derived from the cubic equation at end diastole as follows: LV mass $=0.8$ (1.4) $[$ (interventricular septal dimension at diastole $+\mathrm{LV}$ end-diastolic dimension + posterior wall thickness at diastole $\left.)^{3}-(\text { LV end-diastolic dimension })^{3}\right]+0.6$ (Seddon et al., 2007). The isovolumic relaxation time, marker of the diastolic dysfunction in correlation with the filling pressure, was measured with Doppler imaging using the apical four-chamber view (Cantor et al., 2005). 


\section{HEMODYNAMIC MEASUREMENTS AND CARDIAC SAMPLING}

At the end of the experiments, the rats were anaesthetized as previously described, and the right carotid artery was catheterized (arterial catheter, 3Fr, Vycon) for the recording of systolic, diastolic and mean arterial pressures (PowerLab, AD Instruments). The catheter was then pushed, and the LV end-diastolic pressure (LVEDP) was measured.

Thereafter, a sternotomy was performed. The still-beating heart was rapidly harvested and rinsed in ice-cold $0.9 \% \mathrm{NaCl}$ solution, and the heart and the LV were weighed. The LV-free wall was dissected, and Endo and Epi myocardial samples were extracted under binocular microscopy (Endo and Epi were the innermost and outermost layers of the LV-free wall, respectively). Samples were used immediately for the measurement of mitochondrial function and $\mathrm{H}_{2} \mathrm{O}_{2}$ production.

\section{MYOCARDIAL MITOCHONDRIAL RESPIRATION AND COUPLING}

Mitochondrial respiration in saponin-skinned fibers was studied as previously reported and recently reviewed, ensuring determination of global mitochondrial function within the architectural environment of the muscle fiber (Veksler et al., 1987; Zoll et al., 2006; Kuznetsov et al., 2008). Briefly, fibers were separated and permeabilized in a bath of solution $\mathrm{S}$ containing saponin $(50 \mu \mathrm{g} / \mathrm{mL})$ for $30 \mathrm{~min}$ at $4^{\circ} \mathrm{C}$ with shaking. The permeabilized fibers were then washed for $10 \mathrm{~min}$ with shaking to remove saponin and rinsed twice with the respiratory solution for $5 \mathrm{~min}$ to remove any phosphates. The oxygen consumption of the fibers was measured polarographically using a Clark-type electrode in a 3-mL oxygraphic cell (Strathkelvin Instruments, Glasgow, Scotland). Basal oxygen consumption $\left(V_{0}\right)$ and maximal fiber respiration $\left(V_{\max }\right)$ rates were measured at $22.1^{\circ} \mathrm{C}$ under continuous stirring in the presence of a saturating amount of adenosine diphosphate (ADP) as a phosphate acceptor.

The relative contributions of respiratory chain complexes I, III and IV to global mitochondrial respiratory rates were also determined. When $V_{\max }$ was recorded, the electron flow occurred in complexes I, III, and IV because of the presence of glutamate $(5 \mathrm{mM})$ and malate $(2 \mathrm{mM})$. Complex I was blocked with amytal $(0.02 \mathrm{mM})$, and complex II was stimulated with succinate $(25 \mathrm{mM})$. The measurement of mitochondrial respiration under these conditions permitted the determination of complex II, III, and IV activities $\left(V_{\text {succ }}\right)$. After this measurement was completed, $\mathrm{N}, \mathrm{N}, \mathrm{N}$, N'-tetramethyl-p-phenylenediamine dihydrochloride (TMPD, $0.5 \mathrm{mM})$ and ascorbate $(0.5 \mathrm{mM})$ were added as artificial electron donors to cytochrome c. Under these conditions, the activity of cytochrome c oxidase (complex IV) was increased to its maximum and could be determined as an isolated step in the respiratory chain ( $\left.V_{\text {tmpd }}\right)$. Following the completion of these measurements, the fibers were harvested and dried for $15 \mathrm{~min}$ at $150^{\circ} \mathrm{C}$. Respiration rates are expressed as $\mu \mathrm{mol} \mathrm{O} / 2 / \mathrm{min} / \mathrm{g}$ dry weight.

Concerning mitochondrial coupling, when permeabilized fibers are used instead of isolated mitochondria, endogenous ATPases prevent the establishment of state 4 . The "state 2 " is then used. This state is the basal oxygen consumption under glutamate and malate substrates. The ratio (state 3 rate)/(state 2 rate) is called the acceptor control ratio (ACR) and is viewed as an approach of mitochondrial coupling (Duteil et al., 2010).

\section{$\mathrm{H}_{\mathbf{2}} \mathrm{O}_{\mathbf{2}}$ PRODUCTION IN PERMEABILIZED FIBERS}

The $\mathrm{H}_{2} \mathrm{O}_{2}$ production in response to the sequential addition of substrates and inhibitors was assessed in permeabilized Endo and Epi fibers (Anderson and Neufer, 2006). $\mathrm{H}_{2} \mathrm{O}_{2}$ production was measured with Amplex Red reagent (Invitrogen); this reagent reacts in 1:1 stoichiometry with $\mathrm{H}_{2} \mathrm{O}_{2}$ in a reaction catalyzed by HRP (horseradish peroxidase; Fluka Biochemika) to yield the fluorescent compound resorufin and a molar equivalent $\mathrm{O}_{2}$. Resorufin has excitation/emission wavelengths of 563/587 nm and is highly stable once formed. Fluorescence was measured continuously [change in fluorescence $(\Delta \mathrm{F}) / \mathrm{sec}$ ] with a Fluoromax 4 (Jobin Yvon) spectrofluorometer equipped with temperature control and magnetic stirring. After the baseline in the presence of $\Delta \mathrm{F}$ (reactants only) was established, the reaction was initiated by addition of a permeabilized fiber bundle to $600 \mu \mathrm{L}$ of buffer $\mathrm{Z}$ with glutamate $(5 \mathrm{mM})$ and malate $(2.5 \mathrm{mM})$ as substrates for complex I and succinate $(5 \mathrm{mM})$ as a substrate for complex II. The addition of ADP $(2 \mathrm{mM})$ to the reaction buffer led to a reduction in $\mathrm{H}_{2} \mathrm{O}_{2}$ release, as expected when the electron flow through the respiratory chain is stimulated. Finally, addition of the complex I inhibitor amytal $(2 \mathrm{mM})$ and the complex III inhibitor antimycin $(8 \mu \mathrm{M})$ led to interruption of the normal electron flow and induced an increase in the $\mathrm{H}_{2} \mathrm{O}_{2}$ release.

\section{MITOCHONDRIAL FREE RADICAL LEAK}

The free radical leak correspond to the $\mathrm{H}_{2} \mathrm{O}_{2}$ emission per $\mathrm{O}_{2}$ flux (Picard et al., 2011). $\mathrm{H}_{2} \mathrm{O}_{2}$ production and $\mathrm{O}_{2}$ consumption were measured in parallel in the same sample under similar experimental conditions. This allowed the calculation of the fraction of electrons out of sequence which reduce $\mathrm{O}_{2}$ to ROS in the respiratory chain (the percent of free radical leak) instead of reaching cytochrome oxidase to reduce $\mathrm{O}_{2}$ to water (Anderson et al., 2009). Because two electrons are needed to reduce 1 mole of $\mathrm{O}_{2}$ to $\mathrm{H}_{2} \mathrm{O}_{2}$, whereas four electrons are transferred in the reduction of 1 mole of $\mathrm{O}_{2}$ to water, the percent free radical leak was calculated as the rate of $\mathrm{H}_{2} \mathrm{O}_{2}$ production divided by two times the rate of $\mathrm{O}_{2}$ consumption, and the result was multiplied by 100 (Bouitbir et al., 2012).

\section{CITRATE SYNTHASE ACTIVITY}

We evaluated the global mitochondrial content in Endo and Epi layers by measuring the activity of citrate synthase (Srere, 1969). Citrate synthase activity was expressed as units of activity per gram of tissue wet weight (IU.g ww).

\section{STATISTICAL ANALYSIS}

Values are expressed as the mean \pm standard error of the mean (SEM). Comparisons of the group means were analyzed by the Mann-Whitney test or by a Student $t$-test. $P<0.05$ was considered to be statistically significant. Statistical analysis was performed using the Prism database (GraphPad Prism 5, Graph Pad Software Inc., San Diego, CA, USA). 


\section{RESULTS \\ CLINICAL, ANATOMICAL, AND ECHOCARDIOGRAPHIC CHARACTERISTICS OF THE SHAM-OPERATED AND THE LEFT VENTRICULAR HYPERTROPHY GROUPS}

PO induced LV remodeling with significant cardiac hypertrophy, as inferred from the $31.7 \%$ increase in LV mass (Tables $\mathbf{1}$ and $\mathbf{2}$ ). The LV remodeling was concentric and involved similar thickening of the septal and the posterior walls (Table 2). None of the animals developed clinical evidence of heart failure or impaired systolic or diastolic cardiac functions, as inferred from the normal echocardiographic values of LV fractional shortening, ejection fraction and isovolumic relaxation time and of LV end diastolic pressures in the LVH rats.

\section{REDUCED MITOCHONDRIAL RESPIRATORY CHAIN COMPLEX ACTIVITIES IN CARDIAC HYPERTROPHY}

Mitochondrial respiration measured in situ allows characterization of functional mitochondria in their normal intracellular assembly and position, preserving essential interactions with other organelles. Further, using different mitochondrial

Table 1 | Clinical and anatomical characteristics in sham-operated and LV hypertrophy groups.

\begin{tabular}{lccl}
\hline & $\begin{array}{l}\text { Sham-operated } \\
(\boldsymbol{n}=\mathbf{1 0})\end{array}$ & $\begin{array}{l}\text { LVH } \\
(\boldsymbol{n}=\mathbf{1 0})\end{array}$ & $\boldsymbol{P}$ \\
\hline Heart rate (cycles/min) & $395.68 \pm 10.43$ & $394.51 \pm 12.43$ & NS \\
SAP (mmHg) & $119.09 \pm 3.91$ & $142.46 \pm 8.14$ & 0.016 \\
DAP (mmHg) & $94.85 \pm 5.32$ & $104.59 \pm 9.34$ & NS \\
MAP (mmHg) & $105.3 \pm 3.88$ & $116.54 \pm 9.54$ & NS \\
LVEDP (mmHg) & $6.81 \pm 1.10$ & $7.77 \pm 1.06$ & NS \\
Body weight (g) & $500.30 \pm 11.31$ & $477.80 \pm 24.13$ & NS \\
Heart weight (g) & $0.930 \pm 0.02$ & $1.140 \pm 0.22$ & 0.012 \\
Left ventricle weight (g) & $0.760 \pm 0.01$ & $0.967 \pm 0.07$ & 0.015
\end{tabular}

SAP, systolic arterial pressure; DAP, diastolic arterial pressure; MAP, mean arterial pressure; $L V E D P$, left ventricular end-diastolic pressure, $L V H$, left ventricular hypertrophy; NS: not significant. Values are means \pm S.E.M.

Table 2 | Echocardiographic characteristics in sham-operated and LV hypertrophy groups.

\begin{tabular}{lccl}
\hline & $\begin{array}{l}\text { Sham-operated } \\
(\boldsymbol{n}=\mathbf{1 0})\end{array}$ & $\begin{array}{l}\text { LVH } \\
(\boldsymbol{n}=\mathbf{1 0})\end{array}$ & $\boldsymbol{P}$ \\
\hline LVFS (\%) & $41.93 \pm 1.30$ & $43.47 \pm 1.93$ & NS \\
LVEF (\%) & $77.37 \pm 1.50$ & $78.95 \pm 7.28$ & NS \\
LVEDD (mm) & $7.94 \pm 0.17$ & $8.44 \pm 0.27$ & NS \\
LVESD (mm) & $4.61 \pm 0.12$ & $4.79 \pm 0.30$ & NS \\
Sd (mm) & $1.27 \pm 0.03$ & $1.42 \pm 0.05$ & 0.05 \\
PWd (mm) & $1.15 \pm 0.03$ & $1.40 \pm 0.06$ & 0.007 \\
LVM (g) & $1.07 \pm 0.05$ & $1.41 \pm 0.10$ & 0.02 \\
IVRT (ms) & $23.68 \pm 0.12$ & $23.83 \pm 0.93$ & NS \\
\hline
\end{tabular}

LVFS, left ventricular fractional shortening; LVEF, left ventricular ejection fraction; LVEDD, left ventricular end-diastolic diameter; LVESD, left ventricular end-systolic diameter; $S d$, septum wall thickness in diastole; PWd, posterior wall thickness in diastole; LVM, left ventricular mass; IVRT, isovolumic relaxation time. $L V H$, left ventricular hypertrophy; NS: not significant. Values are means \pm S.E.M. substrates and inhibitors, the relative contributions of respiratory chain complexes I, III, and IV to global mitochondrial respiratory rates can be determined.

Concerning the endocardium, maximal oxidative capacity ( $V_{\text {max }}$; complexes I, III, and IV activities) was significantly decreased in the LVH group $(n=10)$ compared with the sham-operated group $(n=10)(20.1 \pm 1.1$ vs. $26.3 \pm$ $1.6 \mu \mathrm{mol} \mathrm{O} / \mathrm{min} / \mathrm{g}$ dry weight, respectively; $-23.6 \%, P<0.01$; Figure 1A).

In the LVH group, $V_{\text {succi }}$, (complexes II, III, and IV activities) tended to be decreased $(18.9 \pm 1.8$ vs. $23.9 \pm 2.1 \mu \mathrm{mol} \mathrm{O} 2 / \mathrm{min} / \mathrm{g}$ dry weight, respectively; $-20.9 \%, P$ not significant).

$V_{\text {tmpd }}$ (complex IV activity) was significantly decreased $\left(34.1 \pm 2.8\right.$ vs. $43.2 \pm 2.7 \mu \mathrm{mol} \mathrm{O}_{2} / \mathrm{min} / \mathrm{g}$ dry weight, respectively; $-20.8 \%, P=0.04)$.

Concerning the epicardium, similarly, $V_{\max }$ was significantly decreased in the LVH group compared with the sham-operated group $\left(23.9 \pm 0.9\right.$ vs. $35.9 \pm 2.2 \mu \mathrm{mol} \mathrm{O}_{2} / \mathrm{min} / \mathrm{g}$ dry weight, respectively; $-33.3 \%, P<0.001$; Figure 1B). $V_{\text {succi }}$ tended to be lower $\left(22.3 \pm 1.6\right.$ vs. $29.8 \pm 3.6 \mu \mathrm{mol} \mathrm{O}_{2} / \mathrm{min} / \mathrm{g}$ dry weight, respectively; $-25.1 \%, P=0.07)$. $V_{\text {tmpd }}$ was significantly decreased $(38.3 \pm 2.4$ vs. $68.0 \pm 4.4 \mu \mathrm{mol} \mathrm{O} 2 / \mathrm{min} / g$ dry weight, respectively, $-43.6 \%, P<0.001)$.

\section{TRANSMURAL DIFFERENCES IN MITOCHONDRIAL RESPIRATORY CHAIN COMPLEX ACTIVITIES ACROSS THE NORMAL LEFT VENTRICLE AND IN LVH}

To compare both LV layers, weI considered Epi mitochondrial complex activities normalized to their respective Endo values (Figure 1C).

In normal hearts, $V_{\max }$ was $36.5 \%$ lower $(P<0.01)$, $V_{\text {succi }}$ was $24.6 \%$ lower ( $P$ not significant, 0.147$)$ and $V_{\text {tmpd }}$ was $57.4 \%$ lower $(P<0.05)$ in the Endo than in the Epi layers. Thus, normal $\mathrm{LV}$ is characterized by transmural differences in mitochondrial respiratory chain complexes I, III, and IV activities.

In the LVH group, $V_{\max }$ was $19.1 \%$ lower in Endo compared with Epi $(p=0.028)$, but $V_{\text {succi }}$ and $V_{\text {tmpd }}$ decrease $(-18.0$ and $-12.2 \%$, respectively) failed to reached statistical significance.

The ACR $\left(V_{\max } / V_{0}\right)$, representing the degree of coupling between oxidation and phosphorylation, was not different when comparing Epi and Endo LV layers both in sham and LVH rats (Figure 1D).

To determine whether pressure-overload modify the transmural differences in mitochondrial respiratory chain complex activities observed across the normal left ventricle, we compared such transmural gradient using the three main substrates. In the LVH group, the transmural respiratory gradient was significantly lower -as compared to normal LV- for $V_{\text {tmpd }}$ assessing complex IV activity $(-57.4$ vs $-12.2 \%$ for; $P=0.02$, Figure 2$) . V_{\max }$ and $V_{\text {succi }}$ transmural energetic gradient were not significantly reduced in the LVH group ( $P=0.18$ and $P=0.95$, respectively).

\section{ENHANCED PRODUCTION OF REACTIVE OXYGEN SPECIES IN SUBENDOCARDIUM AND SUBEPICARDIUM LAYERS DURING CARDIAC HYPERTROPHY}

$\mathrm{H}_{2} \mathrm{O}_{2}$ production rate was calculated from the slope of $\Delta \mathrm{F} / \mathrm{min}$, after subtracting background, from a standard curve established with the appropriate reaction conditions. At the conclusion of 

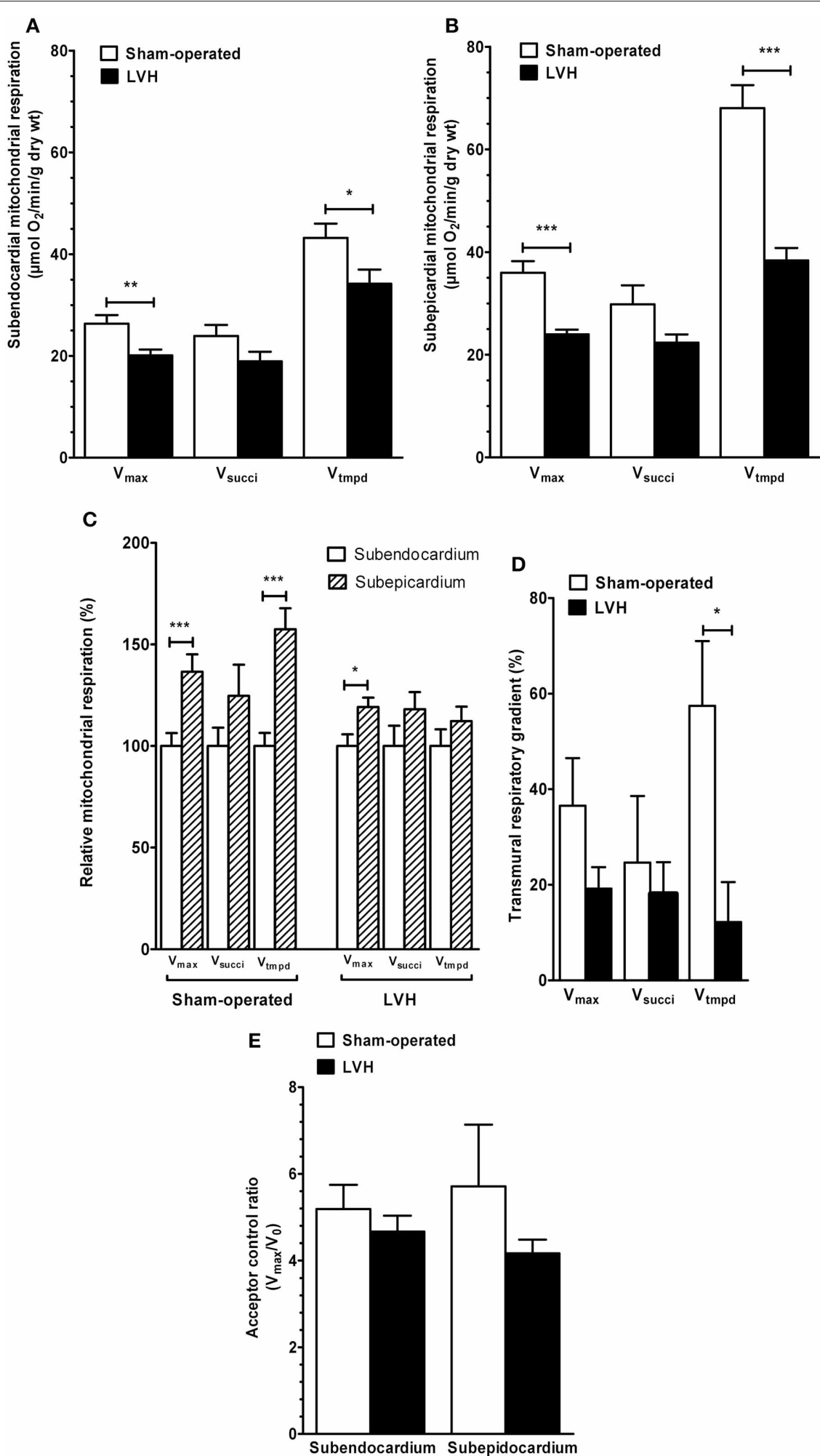

FIGURE 1 | Subendocardium and subepicardium LV mitochondria respiratory chain complex activities and acceptor control ratio in sham-operated and LVH groups. (A) Subendocardium mitochondrial respiratory chain complex activities. (B) Subepicardium mitochondrial respiratory chain complex activities. (C) Relative mitochondrial respiration in subendocardium and subepicardium, with the subendocardium layer considered as the reference (100\%). (D) Transmural differences in mitochondrial respiratory chain complex activities across normal and hypertrophied left ventricles. (E) Subendocardium and subepicardium mitochondrial acceptor control ratio. $V_{\max }$, complexes I, III, and IV activities;

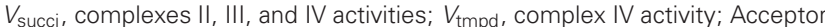
control ratio $\left(V_{\max } / V_{0}\right) ; n=10$ in sham-operated and left ventricular hypertrophy $(\mathrm{LVH})$ groups. Values are means \pm S.E.M. ${ }^{*}, P<0.05$; **, $P<0.01$; *** $P<0.001$. 

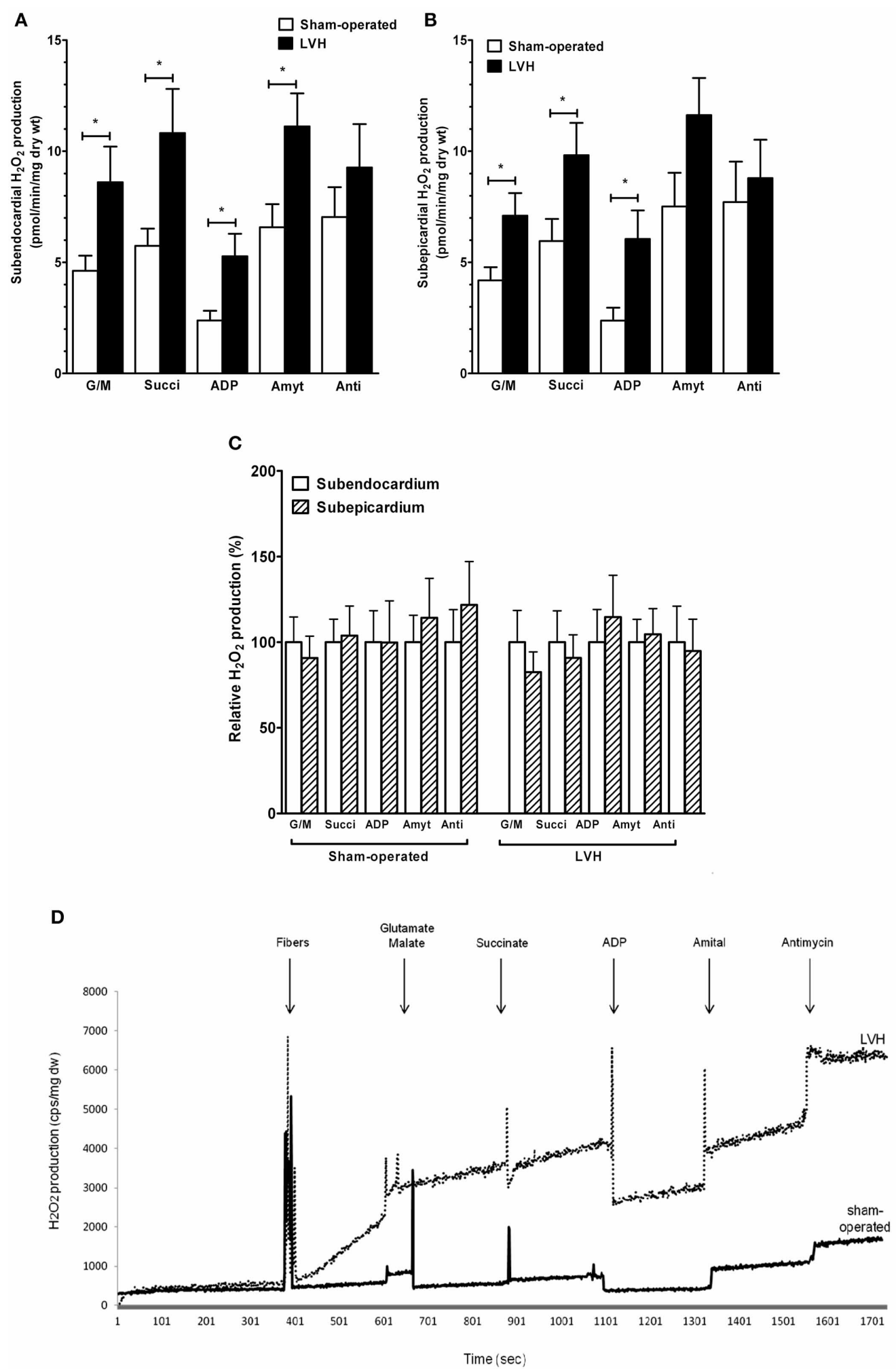

FIGURE 2 | Subendocardium and subepicardium hydrogen peroxide production in sham-operated and LV hypertrophy groups.

(A) Mitochondrial $\mathrm{H}_{2} \mathrm{O}_{2}$ production in subendocardium. (B) Mitochondrial

$\mathrm{H}_{2} \mathrm{O}_{2}$ production in subepicardium. (C) Relative $\mathrm{H}_{2} \mathrm{O}_{2}$ production. (D)

Representative trace of subendocardium $\mathrm{H}_{2} \mathrm{O}_{2}$ production in sham-operated and LV hypertrophy groups. Mitochondrial substrates were sequentially added. G/M, glutamate and malate are complex I substrates; Succi, succinate is complex II substrate; ADP, adenosine diphosphate is ATP synthase substrate; Amyt, amytal is a complex I inhibitor and Anti, antimycin A is a complex III inhibitor. Values are means \pm S.E.M. ${ }^{*}, P<0.05$ 
each experiment, fiber bundles were dried at $150^{\circ} \mathrm{C}, 15 \mathrm{~min}$. $\mathrm{H}_{2} \mathrm{O}_{2}$ production is expressed as picomoles per minute per milligram of dry weight.

The relative contributions of respiratory chain complexes to global mitochondrial $\mathrm{H}_{2} \mathrm{O}_{2}$ production rate were determined using different substrates and inhibitors as depicted in the Figure legend.

The subendocardial mitochondrial $\mathrm{H}_{2} \mathrm{O}_{2}$ production in the presence of the complex I substrates glutamate and malate (Figure 2A) was significantly increased in the LVH group $(n=10)$ compared with the sham-operated animals $(n=10)$ ( $47.3 \pm 8.7$ vs. $25.4 \pm 3.7 \mathrm{pmol} / \mathrm{min} / \mathrm{mg}$ dry weight, respectively; $+86.9 \%, P=0.03)$.

In the presence of the complex II substrate succinate, $\mathrm{H}_{2} \mathrm{O}_{2}$ production was also higher in the LVH group than in the shamoperated group $(59.4 \pm 10.9$ vs. $31.5 \pm 4.24 \mathrm{pmol} / \mathrm{min} / \mathrm{mg}$ dry weight, respectively; $+89.4 \%, P=0.04)$. In the presence of ADP, the $\mathrm{H}_{2} \mathrm{O}_{2}$ release was greater in the LVH group than in the shamoperated group $(29.0 \pm 5.5$ vs. $13.1 \pm 2.4 \mathrm{pmol} / \mathrm{min} / \mathrm{mg}$ dry weight, respectively; $+126.0 \%, P=0.01)$. In the presence of amytal, a complex I inhibitor, the $\mathrm{H}_{2} \mathrm{O}_{2}$ release was higher in the $\mathrm{LVH}$ group than in the sham-operated group (61.1 \pm 8.1 vs. $36.1 \pm$ $5.7 \mathrm{pmol} / \mathrm{min} / \mathrm{mg}$ dry weight, respectively; $+70.7 \%, P=0.02)$. Finally, in the presence of the complex III inhibitor antimycin A, the $\mathrm{H}_{2} \mathrm{O}_{2}$ release tended to be greater in the LVH group.

The subepicardial $\mathrm{H}_{2} \mathrm{O}_{2}$ mitochondrial production in the presence of glutamate and malate (Figure 2B) was significantly increased in the LVH group compared with the sham-operated group $(39.0 \pm 5.6$ vs. $23.0 \pm 3.2 \mathrm{pmol} / \mathrm{min} / \mathrm{mg}$ dry weight, respectively; $+73.1 \%, P=0.02)$. With succinate as the substrate, $\mathrm{H}_{2} \mathrm{O}_{2}$ production was also higher in the LVH group than in the sham-operated group $(53.9 \pm 8.0$ vs. $32.7 \pm 5.4 \mathrm{pmol} / \mathrm{min} / \mathrm{mg}$ dry weight, respectively; $+66.1 \%, P=0.02)$. The $\mathrm{H}_{2} \mathrm{O}_{2}$ release in the presence of ADP was also greater in the LVH group $(33.3 \pm 7.0$ vs. $13.0 \pm 3.1 \mathrm{pmol} / \mathrm{min} / \mathrm{mg}$ dry weight, respectively; $+163.0 \%, P=0.01)$. In the presence of amytal and antimycin A, the $\mathrm{H}_{2} \mathrm{O}_{2}$ release did not differ significantly between the two groups.

The endocardial and epicardial LV production of $\mathrm{H}_{2} \mathrm{O}_{2}$ were similar in normal and in hypertrophied hearts, and no transmural gradient was observed with any substrate in either group (Figure 2C).

Figure 2D shows a representative trace of $\mathrm{H}_{2} \mathrm{O}_{2}$ production in Endo sham-operated and Endo LV hypertrophy groups.

Mitochondrial substrates were sequentially added. G/M, glutamate $(5 \mathrm{mM})$ and malate $(2 \mathrm{mM})$ are complex I substrates; Succi, succinate $(5 \mathrm{mM})$ is complex II substrate; ADP, adenosine diphosphate $(2 \mathrm{mM})$ is ATP synthase substrate; Amyt, amytal $(2 \mathrm{mM})$ is a complex I inhibitor and Anti, antimycin A ( 8 microM) is a complex III inhibitor.

\section{ENHANCED FREE RADICAL LEAK IN SUBENDOCARDIUM AND SUBEPICARDIUM LAYERS DURING CARDIAC HYPERTROPHY}

To further analyze the production of ROS in Endo and Epi layers, we determined the mitochondrial $\mathrm{H}_{2} \mathrm{O}_{2}$ emission per $\mathrm{O}_{2}$ flux corresponding to the mitochondrial free radical leak (Picard et al., 2011).

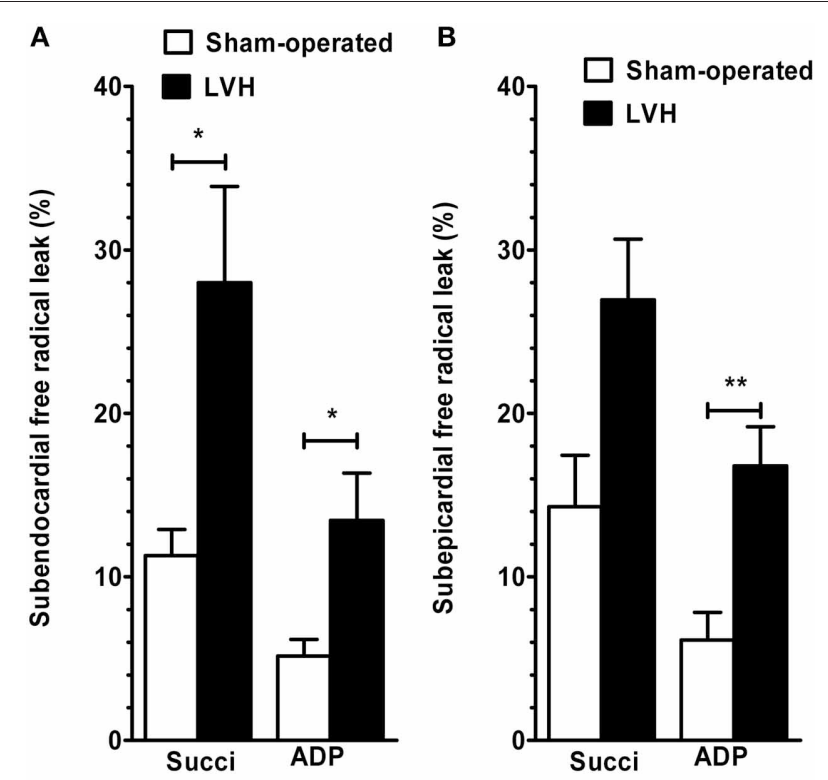

C

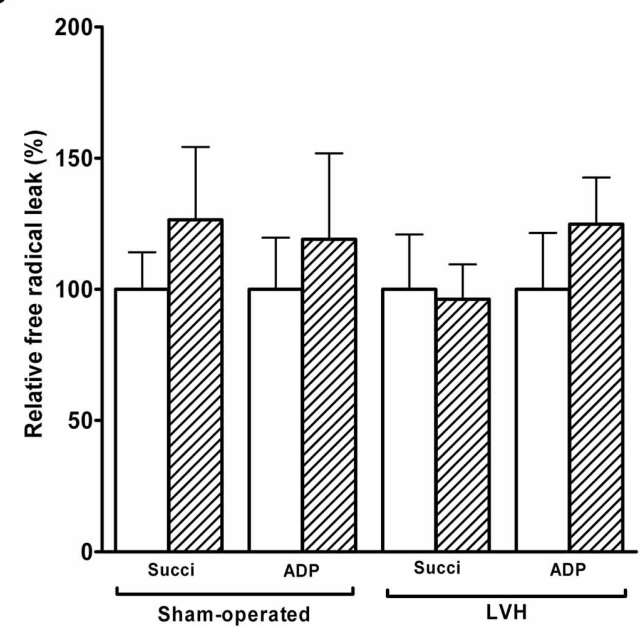

FIGURE 3 | Free radical leak in sham-operated and LV hypertrophy groups. (A) Free radical leak in subendocardium. (B) Free radical leak in subepicardium. (C) Relative free radical leak in subendocardium and subepicardium, with the subendocardium layer considered as the reference $(100 \%)$. The free radical leak represents the fraction of electrons which reduce $\mathrm{O}_{2}$ to $\mathrm{ROS}$ in the respiratory chain $\left(\mathrm{H}_{2} \mathrm{O}_{2}\right.$ emission per $\mathrm{O}_{2}$ flux, expressed in \%). Values are means \pm S.E.M. ${ }^{*}, P<0.05$; ${ }^{* *}$, $P<0.01$.

The Endo mitochondrial free radical leak in the presence of succinate (Figure 3A) was significantly increased in the LVH group compared with the sham-operated animals $(28.0 \pm 15.5$ vs. $11.2 \pm 4.2 \%$, respectively; $+150.0 \%, P=0.03$ ). In the presence of ADP, free radical leak was also higher in the LVH group than in the sham-operated group $(13.4 \pm 2.8$ vs. $5.1 \pm 2.6 \%$, respectively; $+162.7 \%, P=0.01)$.

The Epi free radical leak in the presence of succinate (Figure 3B) was not significantly different in the LVH group compared with the sham-operated group $(26.9 \pm 9.8$ vs. $14.3 \pm 8.2$ 
$\%$, respectively; $+88.1 \%, P=0.07)$. The free radical leak in the presence of ADP was also greater in the LVH group (16.7 \pm 6.3 vs. $6.1 \pm 4.4 \%$, respectively; $+173.7 \%, P=0.004)$.

The endocardial and epicardial LV free radical leak were similar in normal and in hypertrophied hearts, and no transmural gradient was observed with any substrate in either group (Figure 3C).

\section{INCREASED SUBENDOCARDIAL AND SUBEPICARDIAL MITOCHONDRIAL CONTENT IN CARDIAC HYPERTROPHY}

We evaluated the global mitochondrial content in tissues by measuring the citrate synthase activity. During mild cardiac hypertrophy, mitochondrial content increased by 27.2 and 36.3\% in Endo and Epi, respectively (Figure 4). No differences in citrate synthase activity through the different layers of the LV wall were observed either in the sham-operated or the LVH group.

When normalizing the data on CS activity, differences were amplified for respiration and reduced for $\mathrm{H}_{2} \mathrm{O}_{2}$ (Figures 5 and 6).

Thus, Endo and Epi mitochondrial respiratory chain complexes activities were globally decreased in LVH as compared to sham hearts $(-40.0 \%, p=0.0006 ;-37.5 \%, p=0.0093$; and $-37.7 \%, p=0.0012$ for $V_{\max }, V_{\text {succi }}$ and $V_{\text {tmpd }}$ in Endo and $-51.7 \%, p=0.0041 ;-45.4 \%, p=0.073$ and $-58.4 \%, p=$ 0.0006 for $V_{\text {max }}, V_{\text {succi }}$, and $V_{\text {tmpd }}$ in Epi, respectively).

The relative mitochondrial respiration was increased in Epi, as compared to Endo, for $V_{\max }$ and $V_{\text {tmpd }}$ in sham $(+78.9 \%$, $p=0.026$ and $+102.6 \%, p=0.0006$, respectively and for $V_{\text {tmpd }}$ in LVH $(+35.1 \%, p=0.0093)$ but statistical significance of complex 4 transmural gradient decrease in LVH was lost after

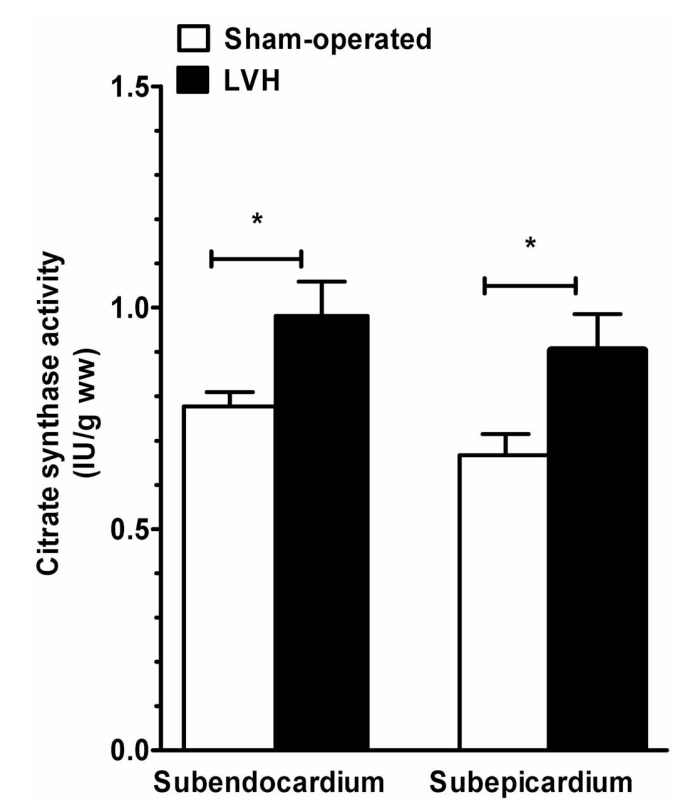

FIGURE 4 | Subendocardium and subepicardium citrate synthase activity in sham-operated and LVH groups. Citrate synthase activity is used to approach global mitochondrial content in tissues and is expressed as units of activity per gram of tissue wet weight (IU.g wW). normalization. Finally, ACR decrease was significant in LVH Epi $(-44.49 \%, p=0.011)$.

Concerning $\mathrm{H}_{2} \mathrm{O}_{2}$ production, after normalizing on citrate synthase activity, LVH Endo and Epi still demonstrated significant increases as compared to sham hearts when using ADP as substrate $(+79.4 \%, p=0.022$ and $+109.1 \%, p=0.027)$ in Endo and Epi, respectively. Again, endo and Epi relative $\mathrm{H}_{2} \mathrm{O}_{2}$ production did not differ in sham and in LVH groups.

\section{DISCUSSION}

The present study demonstrates (1) transmural differences in mitochondrial respiratory chain complex activities across the normal left ventricle, with a lower oxidative capacity of the Endo as compared to the Epi; (2) that aortic-banding-induced mild cardiac hypertrophy decreased mitochondrial oxidative capacities and enhanced hydrogen peroxide production; and (3) that cardiac hypertrophy was associated with a decreased transmural gradient in mitochondrial respiratory chain complex IV activity.

\section{TRANSMURAL DIFFERENCES IN MITOCHONDRIAL RESPIRATORY CHAIN COMPLEX ACTIVITIES ACROSS THE NORMAL LEFT VENTRICLE}

A considerable body of evidence has been accumulated regarding myocardial heterogeneity of the normal heart, including different blood flow, structure, metabolism, electrophysiological, and contractile properties and generally supporting increased mechanical stress and contractility in Endo (Whitty et al., 1976; Smith et al., 1990; Sonntag et al., 1996; Cazorla et al., 2005; Sengupta et al., 2006; Buckberg et al., 2008; Duncker and Bache, 2008; Lou et al., 2011; Van der Velden et al., 2011).

However, few data exist concerning the existence of an energetic gradient across the LV wall. Previous studies using isolated mitochondria showed either similar oxidative capacity in Endo and Epi (Whitty et al., 1976) or increased capacity in Endo (Camici et al., 1984). Respiration studies using isolated mitochondria might results in conflicting results, particularly in the case of small differences, because of nonhomogeneity and fragility of mitochondria submitted to isolation procedures (Sharov et al., 1998). Such limitation might potentially be overcome by using saponin-skinned fibers that ensure global mitochondrial function assessment in intact mitochondria. MacDonald et al. recently investigated transmural differences in respiratory capacity across LV and no transmural respirational difference was observed in healthy rats (MacDonald et al., 2011). These data are in opposition with our results. Similar techniques and animals were used in both studies and further investigations will be useful to clearly explain such a discrepancy.

Indeed, we clearly observed that subendocardial oxidative capacity was significantly lower than subepicardial capacity. These differences hold true for complexes I, III, and IV of the mitochondrial respiratory chain. A key factor that might have been involved in our results is increased ROS production in Endo. Indeed, high oxidative stress has been related to mitochondrial dysfunction in several setting including ischemia-reperfusion and PO (Ingwall, 2009; Charles et al., 2011). Nevertheless, $\mathrm{H}_{2} \mathrm{O}_{2}$ overproduction in Endo was not observed, the relative $\mathrm{H}_{2} \mathrm{O}_{2}$ production being 

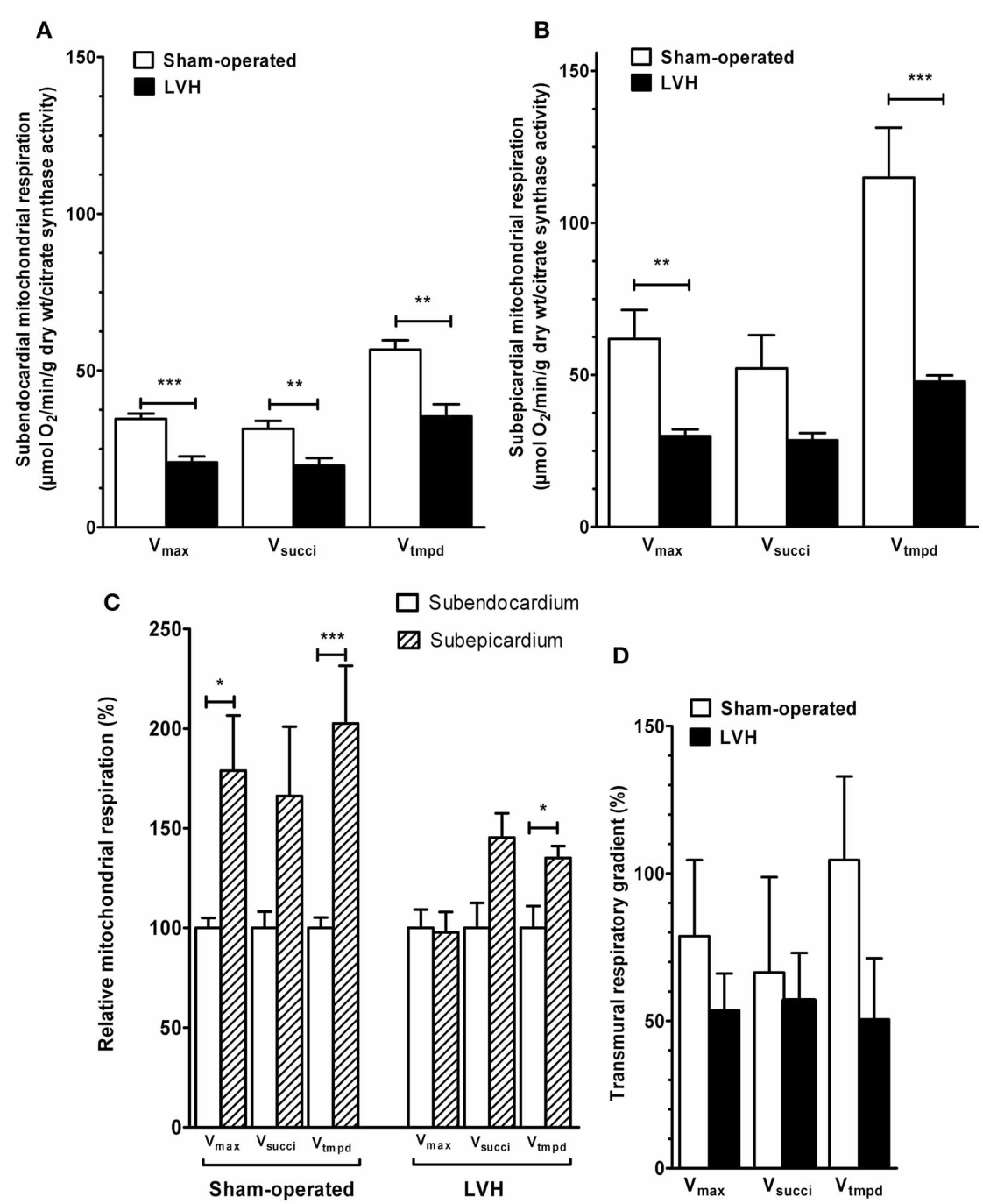

D

E

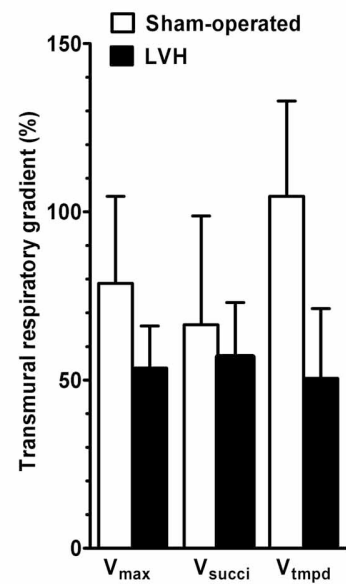

$\square$ Sham-operated

LVH

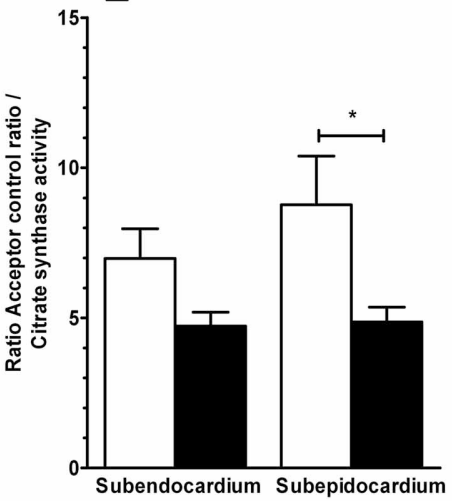

FIGURE 5 | Mitochondrial respiratory chain complex activities and acceptor control ratio in Sham-operated and LVH groups, normalized on citrate synthase activity. (A) Normalized subendocardium mitochondrial respiratory chain complex activities. (B) Normalized subepicardium mitochondrial respiratory chain complex activities. (C) Normalized relative mitochondrial respiration in subendocardium and subepicardium, with the subendocardium layer considered as the reference (100\%).
(D) Normalized transmural differences in mitochondrial respiratory chain complex activities across normal and hypertrophied left ventricles. (E) Normalized acceptor control ratio. $V_{\max }$, complexes I, III, and IV activities;

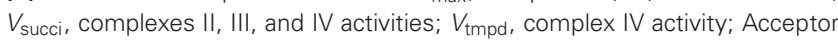
control ratio $\left(V_{\max } / V_{0}\right) ; n=10$ in sham-operated and left ventricular hypertrophy (LVH) groups. Values are means \pm S.E.M. ${ }^{*}, P<0.05$; **, $P<0.01$; *** $P<0.001$. 

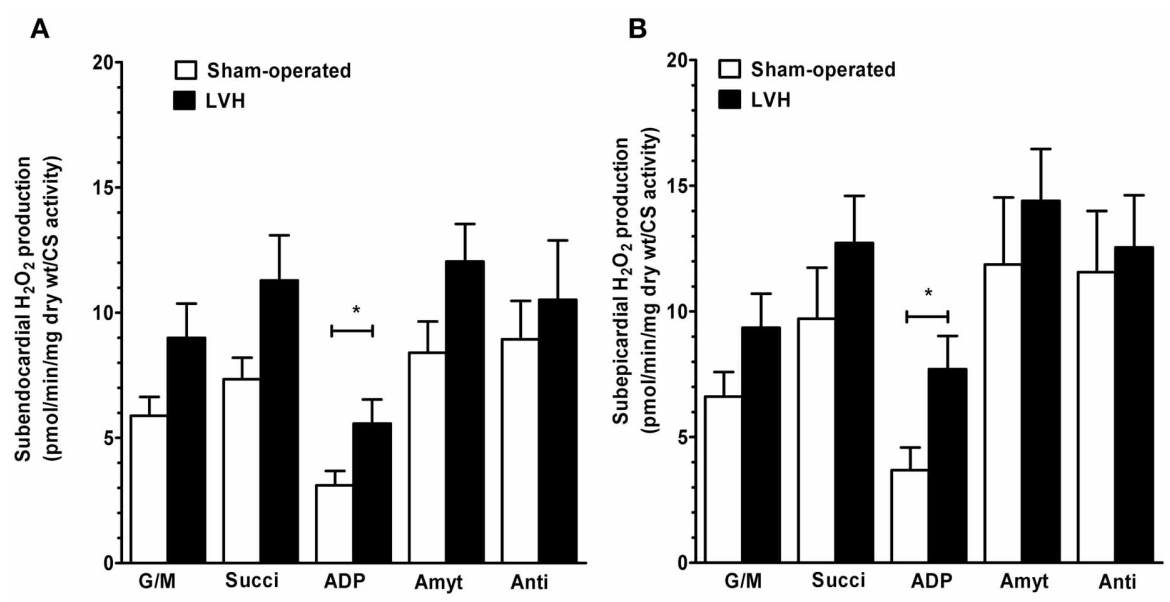

C

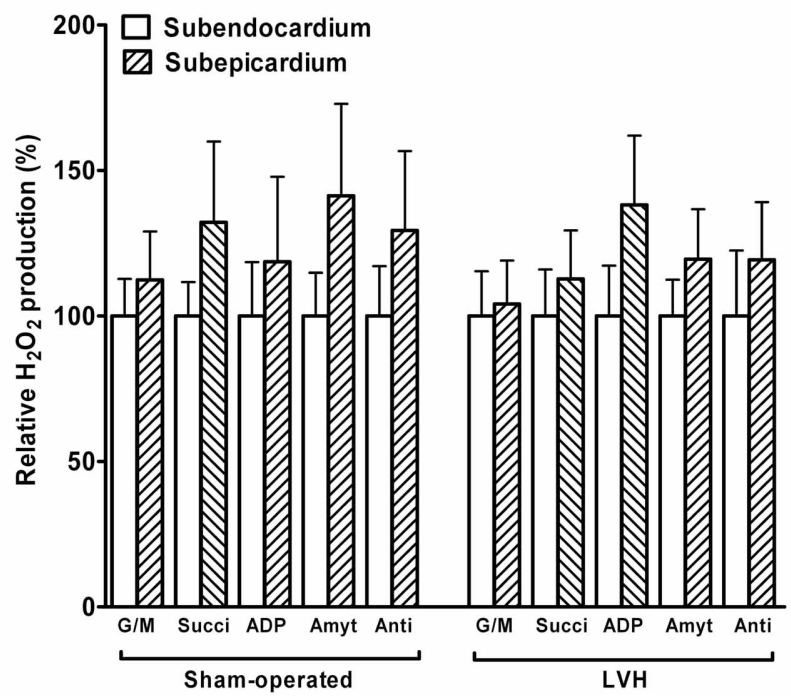

FIGURE 6 | Hydrogen peroxide production in sham-operated and LV hypertrophy groups, normalized on citrate synthase activity.

(A) Normalized mitochondrial $\mathrm{H}_{2} \mathrm{O}_{2}$ production in subendocardium.

(B) Normalized mitochondrial $\mathrm{H}_{2} \mathrm{O}_{2}$ production in subepicardium.

(C) Normalized relative $\mathrm{H}_{2} \mathrm{O}_{2}$ production. Mitochondrial substrates were sequentially added. G/M, glutamate and malate are complex I substrates; Succi, succinate is complex II substrate; ADP, adenosine diphosphate is ATP synthase substrate; Amyt, amytal is a complex I inhibitor and Anti, antimycin $A$ is a complex III inhibitor. Values are means \pm S.E.M. $*, P<0.05$. similar in both LV layers. Similar data were observed in LVH, further supporting that hydrogen peroxide did not explain the transmural gradient seen in mitochondrial respiration.

\section{MILD CARDIAC HYPERTROPHY IMPAIRS SUBENDOCARDIAL AND SUBEPICARDIAL MITOCHONDRIAL RESPIRATORY CHAIN COMPLEX ACTIVITIES}

Surprisingly, increased maximal oxidative capacity was transiently observed using isolated mitochondria in a thoracic aortic banding model. In this study, maximal respiratory capacity was greater than control in the first 6 weeks, normal after 10 weeks and significantly reduced after 20 weeks (Doenst et al., 2010). This might correspond to a first compensated phase, mitochondrial dysfunction occurring thereafter when ejection fraction was decreasing. Accordingly, it is generally accepted that mitochondrial dysfunction is observed at the stage of heart failure (Ventura-Clapier et al., 2001). In particular, energetic impairment has been reported when $\mathrm{LVH}$ is associated with cardiac dysfunction (Ventura-Clapier et al., 2001; Ali et al., 2011). A decreased rate of substrate oxidation predicts the onset of contractile dysfunction and heart failure in rats with PO (Neubauer, 2007; Jameel and Zhang, 2009; Doenst et al., 2010). However, whether mitochondrial dysfunction might be differently involved in endocardium as compared to epicardium during PO-induced mild cardiac hypertrophy development deserve further studies. 
In the present work, for the first time, we observed that mitochondrial respiratory chain complex activities are significantly reduced in both the subendocardial and subepicardial LV layers in compensated LVH. This might be clinically relevant since our model of 6 weeks abdominal aortic banding induced an increase in LV mass of $31.7 \%$ with no clinical signs of heart failure and no changes in LVEDP, LV diameter, LV ejection fraction, LV fractional shortening, or IVRT. Furthermore, we used saponinpermeabilized fibers, which allow the determination of global mitochondrial function with respect to the mitochondrial architectural environment (Zoll et al., 2002). Similarly, MacDonald et al. also recently reported an early impairment in mitochondrial respiration in steptozotocin-induced diabetes (MacDonald et al., 2011).

Although mitochondrial uncoupling should not always be seen as deleterious (Duteil et al., 2010; Tran et al., 2012), besides mitochondrial respiratory chain activities impairment, PO might be associated with mitochondrial uncoupling particularly in case of heart failure. Accordingly, Faerber's et al. observed not only reduced respiratory rates but also reduced mitochondrial coupling in mice hearts after aortic banding performed between the brachiocephalic trunk and the left carotid artery (Faerber et al., 2011). Thus, a loss of efficiency in ATP production was observed both in the failing hearts and in cardiac hypertrophy without heart failure. In our study, at a global muscle level, we did not observe mitochondrial uncoupling. The smaller degree of $\mathrm{LVH}$ in our rats likely explains their maintained mitochondrial coupling.

\section{MILD CARDIAC HYPERTROPHY IS ASSOCIATED WITH INCREASED MITOCHONDRIAL HYDROGEN PEROXIDE PRODUCTION AND FREE RADICAL LEAK}

Excessive ROS generation likely participates in cardiac hypertrophy-associated mitochondrial damage (Pimentel et al., 2001; Seddon et al., 2007; Takimoto and Kass, 2007), and the sources of ROS production during cardiac hypertrophy deserve further investigation. Uncoupled nitric oxide synthetase, xanthine oxidoreductase, and NADPH oxidase might be important mediators of PO-induced LVH. However, a role of mitochondria in generating ROS in the setting of cardiac hypertrophy is also likely (Seddon et al., 2007). Indeed, the role of mitochondria extends far beyond energy production because mitochondria are important generators of ROS that can act as a source of cellular damage depending on the amount of ROS produced (Bouitbir et al., 2011).

Mitochondria are both causes and targets of ROS, and mitochondrial production of $\mathrm{H}_{2} \mathrm{O}_{2}$ might be increased as a result of $\mathrm{LVH}$-associated mitochondrial dysfunction. The use of saponin-permeabilized fibers allowed us to study $\mathrm{H}_{2} \mathrm{O}_{2}$ production by mitochondria. The data thus obtained support the idea that mitochondria participate significantly in hypertrophy-related oxidative stress. Indeed, subendocardial and subepicardial $\mathrm{H}_{2} \mathrm{O}_{2}$ production was significantly enhanced in $\mathrm{LVH}$ compared to normal hearts. Accordingly, the free radical leak increased in LVH, supporting that the fraction of electrons which reduce $\mathrm{O}_{2}$ to ROS in the respiratory chain (Anderson et al., 2009; Bouitbir et al., 2012) was greater in pressure-overloaded hearts. This was observed in Endo and Epi and thus mitochondria located in both LV layers participated in the ROS overproduction of the hypertrophied hearts.

\section{MILD CARDIAC HYPERTROPHY IS ASSOCIATED WITH A DECREASED TRANSMURAL GRADIENT IN MITOCHONDRIAL RESPIRATORY CHAIN COMPLEX IV ACTIVITY}

Interestingly, transmural complex IV activity was significantly reduced in LVH as compared to sham animals. Cardiac hypertrophy reduced such LV transmural gradient mainly through a decrease in subepicardial mitochondrial respiration.

A similar result has been reported during dobutamine-induced demand ischemia. Indeed, Jameel et al. observed in a stenotic perfused coronary bed during dobutamine-induced high cardiac work state, that the Epi showed greater metabolic changes than the Endo layer (Jameel et al., 2008). Although both settings were different, these two results might suggest that the sensitivity of the LV Epi layer might be increased in case of preexisting pathology as compared to normal LV submitted to recent injury.

Whether mitochondrial dysfunction is not a major causative factor in the eventual failure of the LV cannot be inferred from our data since our model was not characterized by heart failure. Nevertheless, one might propose that the relatively light degree of LVH explains that only complex IV activity of the mitochondrial respiratory chain was significantly reduced as compared to sham heart. Further studies would be useful to determine whether greater LVH with beginning cardiac failure will be associated with a reduced LV transmural differences in all mitochondrial respiratory chain complexes activities. In this case, such a reduced transmural mitochondrial respiratory gradient might be a new marker of the transition from uncomplicated to complicated LVH.

\section{INCREASED SUBENDOCARDIAL AND SUBEPICARDIAL MITOCHONDRIAL CONTENT IN CARDIAC HYPERTROPHY}

It has been generally reported a reduced mitochondrial biogenesis in case of LVH, but mainly in case of decompensated pathological hypertrophy. Accordingly, Abel and Doenst recently proposed that mitochondrial biogenesis might be enhanced or maintained during physiological or compensated pathological hypertrophy, respectively (Abel and Doenst, 2011). In our study, the global mitochondrial content in tissues increased but mitochondrial oxidative capacity decreased concomitantly. Thus, as expected, our model likely allowed to explore LVH located just before a decompensated state.

Data can be normalized on CS in an attempt to view the results not as a whole but as data per unit of mitochondria. However, in this study, we performed citrate synthase analysis as additional measurements. Fibers were not the same than those used for mitochondrial respiration or $\mathrm{H}_{2} \mathrm{O}_{2}$ production, possibly decreasing the pertinence of such analysis. Accordingly, study normalizing respiration on citrate synthase used frozen myofibers bundles from respiratory assays (Picard et al., 2011). Despite this technical limitation, to discuss normalized data on CS activity appears interesting. 
Considering both normal heart and LVH, the data obtained without normalization are globally confirmed. Thus, differences were amplified for respiration and reduced for $\mathrm{H}_{2} \mathrm{O}_{2}$. To overcome the limitation related to the use of different fibers for $\mathrm{H}_{2} \mathrm{O}_{2}$ production and CS measurements, we determined the free radical leak, allowing determine mitochondrial ROS production on same fibers, matching respiration values with matched substrates. Such analysis confirmed that ROS originating from mitochondria were increased in LVH.

Concerning a potential transmural gradient in ROS production in normal heart, all analysis demonstrated no difference between Endo and Epi layers. This held true in LVH and supports that hydrogen peroxide does not explain the normal transmural gradient seen in respiration. Concerning the complex IV activity transmural gradient difference between normal heart and LVH, the statistical significance was lost when normalizing it on CS activity. This suggest caution in the interpretation of the data, as presented below.

\section{LIMITATIONS OF THE STUDY}

In case of obesity, an increased effect of blood pressure has been observed on LV growth resulting in a steeper slope of the blood pressure-LV mass index relation (Norton et al., 2009). Impaired pathways controlling cellular growth and proliferation appeared to be related to increased oxidative stress (Mandavia et al., 2012) and dietary-induced obesity has been shown to hasten the progression from concentric LV hypertrophy to pump dysfunction in SHR rats (but not in WKY control rats), independently of blood pressure changes (Majane et al., 2009). Since our animal weights were located at the upper limit of the normal range, it is possible that pressure-overload effects might have been enhanced as compared to animals with lower body weight.

Only part of the transmural difference in mitochondrial respiratory chain complex activities seen across the normal left ventricle was decreased in LVH. Since the statistical significance was lost when normalizing on citrate synthase activity, it might be viewed as no physiologically important. We believe that this is likely to be due to the relatively small degree of LVH in our experimental model and that even a small transmural difference might be pertinent. Indeed, keeping on mitochondrial function, for instance, very slight mitochondrial uncoupling of about $12 \%$ has been shown to be beneficial, protecting mice against decreased muscle oxidative capacities induced by sedentariness, development of type 2 diabetes and against high-caloric diet induced obesity (Duteil et al., 2010).

In summary, our data support a transmural difference in mitochondrial respiratory chain complex activities across the normal left ventricle, with a lower oxidative capacity of the Endo as compared to the Epi.

PO-induced mild cardiac hypertrophy was characterized by reduced mitochondrial respiratory chain complex activities associated with increased hydrogen peroxide production.

Additionally, cardiac hypertrophy might be associated with a decreased transmural gradient in mitochondrial respiratory chain complex IV activity. To determine whether these changes may be a hallmark in LVH time course needs further work aiming to investigate whether maladaptive hypertrophy is associated with a loss of LV transmural energetic gradient.

\section{ACKNOWLEDGMENTS}

We thank Fabienne Goupilleau, Isabelle Bentz, Anne-Marie Medina, and Anne Schmitt for their expert biological and secretarial assistance. We are grateful to the Professor N. Meyer, from the department of Public Health, for his assistance in the statistical analysis of the data.

\section{FUNDING}

This work was supported by a grant from OCOVAS (“Cardiovascular operated patients association").

\section{REFERENCES}

Abel, E. D., and Doenst, T. (2011). Mitochondrial adaptations to physiological vs. pathological cardiac hypertrophy. Cardiovasc. Res. 90, 234-342.

Ali, A., Patel, A., Ali, Z., Abu-Omar, Y., Saeed, A., Athanasiou, T., and Pepper, J. (2011). Enhanced left ventricular mass regression after aortic valve replacement in patients with aortic stenosis is associated with improved long-term survival. J. Thorac. Cardiovasc. Surg. 142, 285-291.

Anderson, E. J., Kypson, A. P., Rodriguez, E., Anderson, C. A., Lehr, E. J., and Neufer, P. D. (2009). Substrate-specific derangements in mitochondrial metabolism and redox balance in the atrium of the type 2 diabetic human heart. J. Am. Coll. Cardiol. 54, 1891-1898.

Anderson, E. J., and Neufer, P. D. (2006). Type II skeletal myofibers possess unique properties that potentiate mitochondrial $\mathrm{H}(2) \mathrm{O}(2)$ generation. Am. J. Physiol. Cell Physiol. 290, C844-C851.

Bouitbir, J., Charles, A. L., EchanizLaguna, A., Kindo, M., Daussin, F., Auwerx, J., Piquard, F., Geny, B., and Zoll, J. (2011). Opposite effects of statins on mitochondria of cardiac and skeletal muscles: a 'mitohormesis' mechanism involving reactive oxygen species and PGC-1. Eur. Heart J. 33, 1397-1407.

Bouitbir, J., Daussin, F., Charles, A. L., Rasseneur, L., Dufour, S., Richard, R., Piquard, F., Geny, B., and Zoll,
J. (2012). Mitochondria of trained skeletal muscle are protected from deleterious effects of statins. Muscle Nerve. doi: 10.1002/mus.23309

Buckberg, G., Hoffman, J. I., Mahajan, A., Saleh, S., and Coghlan, C. (2008). Cardiac mechanics revisited: the relationship of cardiac architecture to ventricular function. Circulation 118, 2571-2587.

Camici, P., Ursini, F., Galiazzo, F., Bellitto, L., Pelosi, G., Marzilli, M., L'Abbate, A., and Barsacchi, R. (1984). Different respiratory activities of mitochondria isolated from the subendocardium and subepicardium of the canine heart. Basic Res. Cardiol. 79, 454-460.

Cantor, E. J., Babick, A. P., Vasanji, Z., Dhalla, N. S., and Netticadan, T. (2005). A comparative serial echocardiographic analysis of cardiac structure and function in rats subjected to pressure or volume overload. J. Mol. Cell. Cardiol. 38, 777-786.

Cazorla, O., Szilagyi, S., Le Guennec, J. Y., Vassort, G., and Lacampagne, A. (2005). Transmural stretchdependent regulation of contractile properties in rat heart and its alteration after myocardial infarction. FASEB J. 19, 88-90.

Charles, A. L., Guilbert, A. S., Bouitbir J., Goette-Di Marco, P., Enache, I., Zoll, J., Piquard, F., and Geny, B. (2011). Effect of postconditioning on mitochondrial dysfunction in experimental aortic cross-clamping. Br. J. Surg. 24, 511-516.

Doenst, T., Pytel, G., Schrepper, A., Amorim, P., Färber, G., Shingu, 
Y., Mohr, F. W., and Schwarzer, M. (2010). Decreased rates of substrate oxidation ex vivo predict the onset of heart failure and contractile dysfunction in rats with pressure overload. Cardiovasc. Res. 86, 461-470.

Drazner, M. H. (2011). The progression of hypertensive heart disease. Circulation 123, 327-334.

Duncker, D. J., and Bache, R. J. (2008). Regulation of coronary blood flow during exercise. Physiol. Rev. 88, 1009-1086.

Duteil, D., Chambon, C., Ali, F., Malivindi, R., Zoll, J., Kato, S., Geny, B., Chambon, P., and Metzger, D. (2010). The transcriptional coregulators TIF2 and SRC-1 regulate energy homeostasis by modulating mitochondrial respiration in skeletal muscles. Cell Metab. 12, 496-508.

Faerber, G., Barreto-Perreia, F., Schoepe, M., Gilsbach, R., Schrepper, A., Schwarzer, M., Mohr, F. W., Hein, L., and Doenst, T. (2011). Induction of heart failure by minimally invasive aortic constriction in mice: reduced peroxisome proliferator-activated receptor $\gamma$ coactivator levels and mitochondrial dysfunction. $J$. Thorac. Cardiovasc. Surg. 141, 492-500.

Gallego-Delgado, J., Lazaro, A., Osende, J. I., Barderas, M. G., Duran, M. C., Vivanco, F., and Egido, J. (2006). Comparison of the protein profile of established and regressed hypertension-induced left ventricular hypertrophy. J. Proteome Res. 5, 404-413.

Geshi, E., Konno, N., Yanagishita, T., and Katagiri, T. (1988). Impairment of mitochondrial respiratory activity in the early ischemic myocardium-with special reference to electron transport system. Jpn. Circ. J. 52, 535-542.

Griffiths, E. R., Friehs, I., Scherr, E., Poutias, D., McGowan, F. X., and Del Nido, P. J. (2010). Electron transport chain dysfunction in neonatal pressure-overload hypertrophy precedes cardiomyocyte apoptosis independent of oxidative stress. J. Thorac. Cardiovasc. Surg. 139, 1609-1617.

Ingwall, J. S. (2009). Energy metabolism in heart failure and remodelling. Cardiovasc. Res. 81, 412-419.

Jameel, M. N., Wang, X., Eijgelshoven, M. H., Mansoor, A., and Zhang, J. (2008). Transmural distribution of metabolic abnormalities and glycolytic activity during dobutamineinduced demand ischemia. Am. J. Physiol. Heart Circ. Physiol. 6, H2680-H2686.

Jameel, M. N., and Zhang, J. (2009). Myocardial energetics in left ventricular hypertrophy. Curr. Cardiol. Rev. 5, 243-250.

Kuznetsov, A. V., Veksler, V., Gellerich, F. N., Saks, V., Margreiter, R., and Kunz, W. S. (2008). Analysis of mitochondrial function in situ in permeabilized muscle fibers, tissues and cells. Nat. Protoc. 3, 965-976.

Lou, Q., Fedorov, V. V., Glukhov, A. V., Moazami, N., Fast, V. G., and Efimov, I. R. (2011). Transmural heterogeneity and remodeling of ventricular excitationcontraction coupling in human heart failure. Circulation 123 1881-1890.

MacDonald, J. R., Oellermann, M., Rynbeck, S., Chang, G., Ruggiero, K., Cooper, G. J., and Hickey, A. J. (2011). Transmural differences in respiratory capacity across the rat left ventricle in health, aging, and streptozotocininduced diabetes mellitus: evidence that mitochondrial dysfunction begins in the subepicardium. Am. J. Physiol. Cell Physiol. 300, C246-C255.

Majane, O. H., Vengethasamy, L., du Toit, E. F., Makaula, S., Woodiwiss, A. J., and Norton, G. R. (2009). Dietary-induced obesity hastens the progression from concentric cardiac hypertrophy to pump dysfunction in spontaneously hypertensive rats. Hypertension 54, 1376-1383.

Mandavia, C. H., Pulakat, L., Demarco, V., and Sowers, J. R. (2012). Over-nutrition and metabolic cardiomyopathy. Metab. Clin. Exp. doi: 10.1016/j.metabol.2012.02.013

Murdoch, C. E., Zhang, M., Cave, A. C., and Shah, A. M. (2006). NADPH oxidase-dependent redox signalling in cardiac hypertrophy, remodelling and failure. Cardiovasc. Res. 71, 208-215.

Nabeebaccus, A., Zhang, M., and Shah, M. A. (2011). NADPH oxidase and cardiac remodeling. Heart Fail. Rev. $16,5-12$.

Neubauer, S. (2007). The failing heartan engine out of fuel. N. Engl. J. Med. 356, 1140-1151.

Norton, G. R., Majane, O. H., Libhaber, E., Maseko, M. J., Makaula, S., Libhaber, C., and Woodiwiss, A. J. (2009). The relationship between blood pressure and left ventricular mass index depends on an excess adiposity. J. Hypertens. 27, 1873-1883.

Opie, L. H., Commerford, P. J., Gersh, B. J., and Pfeffer, M. A (2006). Controversies in ventricular remodelling. Lancet $367,356-367$.

Picard, M., Ritchie, D., Thomas, M. M., Wright, K. J., and Hepple, R. T. (2011). Alterations in intrinsic mitochondrial function with aging are fiber type-specific and do not explain differential atrophy between muscles. Aging Cell 10, 1047-1055.

Pimentel, D. R., Amin, J. K., Xiao L., Miller, T., Viereck, J., OliverKrasinski, J., Baliga, R., Wang, J., Siwik, D. A., Singh, K., Pagano, P., Colucci, W. S., and Sawyer, D. B. (2001). Reactive oxygen species mediate amplitude-dependent hypertrophic and apoptotic responses to mechanical stretch in cardiac myocytes. Circ. Res. 89, 453-460.

Rimbaud, S., Sanchez, H., Garnier, A., Fortin, D., Bigard, X., Veksler, V., and Ventura-Clapier, R. (2009). Stimulus specific changes of energy metabolism in hypertrophied heart. J. Mol. Cell. Cardiol. 46, 952-959.

Seddon, M., Looi, Y. H., and Shah, A. M. (2007). Oxidative stress and redox signalling in cardiac hypertrophy and heart failure. Heart 93 , 903-907.

Sengupta, P. P., Korinek, J., Belohlavek, M., Narula, J., Vannan, M. A., Jahangir, A., and Khandheria, B. K. (2006). Left ventricular structure and function: basic science for cardiac imaging. J. Am. Coll. Cardiol. 48, 1988-2001.

Sharov, V. G., Goussev, A., Lesch, M., Goldstein, S., and Sabbah, H. N. (1998). Abnormal mitochondrial function in myocardium of dogs with chronic heart failure. J. Mol. Cell. Cardiol. 30, 1757-1762.

Smith, S. H., Kramer, M. F., Reis, I., Bishop, S. P., and Ingwall, J. S. (1990). Regional changes in creatine kinase and myocyte size in hypertensive and nonhypertensive cardiac hypertrophy. Circ. Res. 67, 1334-1344.

Sonntag, M., Deussen, A., Schultz, J., Loncar, R., Hort, W., and Schrader, J. (1996). Spatial heterogeneity of blood flow in the dog heart. I. Glucose uptake, free adenosine and oxidative/glycolytic enzyme activity. Pflugers Arch. 432, 439-450.

Srere, P. A. (1969). Citrate synthase. Meth. Enzymol. 13, 3-11.

Takimoto, E., and Kass, D. A. (2007). Role of oxidative stress in cardiac hypertrophy and remodeling. Hypertension 49, 241-248.
Tran, T. N., Noll, E., Collange, O., Bouitbir, J., Charles, A. L., Kindo, M., Zoll, J., Diemunsch, P., and Geny, B. (2012). Mitochondrial respiratory chain uncoupling, oxidative stress and skeletal muscle energetics. Skeletal Muscle Physiol. Classif. Dis.

Van Bilsen, M., Van Nieuwenhoven, F. A., and Van der Vusse, G. J. (2009). Metabolic remodelling of the failing heart: beneficial or detrimental? Cardiovasc. Res. 81, 420-428.

Van der Velden, J., Merkus, D., de Beer, V., Hamdani, N., Linke, W. A., Boontje, N. M., Stienen, G. J., Duncker, D. J. (2011) Transmural heterogeneity of myofilament function and sarcomeric protein phosphorylation in remodeled myocardium of pigs with a recent myocardial infarction. Front. Physiol. 2:83. doi: 10.3389/fphys.2011.00083

Veal, E. A., Day, A. M., and Morgan, B. A. (2007). Hydrogen peroxide sensing and signalling. Mol. Cell 26, $1-14$

Veksler, V. I., Kuznetsov, A. V., Sharov, V. G., Kapelko, V. I., and Saks, V. A. (1987). Mitochondrial respiratory parameters in cardiac tissue: a novel method of assessment by using saponin-skinned fibers. Biochim. Biophys. Acta 892, 191-196.

Ventura-Clapier, R., Garnier, A., Veksler, V., and Joubert, F. (2001). Bioenergetics of the failing heart. Biochim. Biophys. Acta 1813, 1360-1372.

Whitty, A. J., Dimino, M. J., Elfont, E. A., Hughes, G. W., and Repeck, M. W. (1976). Transmural mitochondrial differences in myocardium. Recent Adv. Stud. Cardiac Struct. Metab. 11, 349-354.

Zoll, J., Monassier, L., Garnier, A., N'Guessan, B., Mettauer, B., Veksler, V., Piquard, F., Ventura-Clapier, R., and Geny, B. (2006). ACE inhibition prevents myocardial infarctioninduced skeletal muscle mitochondrial dysfunction. J. Appl. Physiol. 101, 385-391.

Zoll, J., Ponsot, E., Doutreleau, S., Mettauer, B., Piquard, F., Mazzucotelli, J. P., Diemunsch, P., and Geny, B. (2005). Acute myocardial ischemia induces specific alterations of ventricular mitochondrial function in experimental pigs. Acta Physiol. Scand. 185, 25-32.

Zoll, J., Sanchez, H., N'Guessan, B. Ribera, F., Lampert, E., Bigard, X., Serrurier, B., Fortin, D., Geny, B., Veksler, V., Ventura-Clapier, R., and Mettauer, B. (2002). Physical 
activity changes the regulation of mitochondrial respiration in human skeletal muscle. J. Physiol. 543, 191-200.

Conflict of Interest Statement: The authors declare that the research was conducted in the absence of any commercial or financial relationships that could be construed as a potential conflict of interest.

Received: 23 April 2012; accepted: 29 July 2012; published online: 28 August 2012. Citation: Kindo M, Gerelli S, Bouitbir J, Charles A-L, Zoll J, Hoang Minh T, Monassier L, Favret F, Piquard F and Geny B (2012) Pressure overloadinduced mild cardiac hypertrophy reduces left ventricular transmural differences in mitochondrial respiratory chain activity and increases oxidative stress. Front. Physio. 3:332. doi: 10.3389/ fphys.2012.00332

This article was submitted to Frontiers in Cardiac Muscle Physiology, a specialty of Frontiers in Physiology.

Copyright (C) 2012 Kindo, Gerelli, Bouitbir, Charles, Zoll, Hoang Minh,
Monassier, Favret, Piquard and Geny. This is an open-access article distributed under the terms of the Creative Commons Attribution License, which permits use, distribution and reproduction in other forums, provided the original authors and source are credited and subject to any copyright notices concerning any third-party graphics etc. 